\title{
Teachers' Beliefs about the Possibilities and Limitations of Digital Games in Classrooms
}

\author{
CATHERINE BEAVIS, ${ }^{1}$ LEONIE ROWAN, ${ }^{1}$ MICHAEL DEZUANNI, ${ }^{2}$ CHRISTIE \\ MCGILLIVRAY, ${ }^{3}$ JOANNE O'MARA, ${ }^{3}$ SARAH PRESTRIDGE, ${ }^{1}$ COLLEEN \\ STIELER-HUNT,${ }^{4}{ }^{\text {ROBERTA THOMPSON }}{ }^{1} \&$ JASON ZAGAMI ${ }^{1}$ \\ ${ }^{1}$ Griffith University, Gold Coast, QLD, Australia; ${ }^{2}$ Queensland University of Technology, \\ Kelvin Grove, QLD, Australia; ${ }^{3}$ Deakin University, Burwood, VIC, Australia; ${ }^{4}$ University of \\ the Sunshine Coast, Maroochydore DC, QLD, Australia
}

\begin{abstract}
Teachers' beliefs about what it is (or is not) possible to achieve with digital games in educational contexts will inevitably influence the decisions that they make about how, when, and for what specific purposes they will bring these games into their classrooms. They play a crucial role in both shaping and responding to the complex contextual factors which influence how games are understood and experienced in educational settings. Throughout this article the authors draw upon data collected for a large-scale, mixed-methods research project focusing on literacy, learning and teaching with digital games in Australian classrooms, to focus explicitly on the attitudes, understandings and expectations held about digital games by diverse teachers at the beginning of the project. They seek to identify the beliefs about games that motivated teachers' participation in a digital games research project while focusing, as well, on concerns that teachers express about risks or limitations of such a project. The authors' aim is to develop a detailed picture of the mindsets that teachers bring to games-based learning environments, and the relevance of these mindsets to broader debates about the relationship between games, learning and school.
\end{abstract}

\section{Introduction}

The immense popularity of games with wide and diverse groups of people has supported the development of a burgeoning industry focused on developing 'serious' games and associated learning materials for use within schools (Davidson, 2008), and the adaptation or incorporation of commercial off-the-shelf and other games for classroom learning purposes. There is considerable interest in the potential of games to support learning, with a number of studies (e.g. McFarlane et al, 2002; Francis, 2006; Mehotra et al, 2012) documenting the use of games in the classroom and describing the underlying learning principles and pedagogies entailed. Such studies are exemplary. However, as reviews of the field of games-based learning note, (Perrotta et al, 2013), problems arise when digital games are designed for and/or introduced into schools with a limited awareness of the role that context plays in a gaming experience and/or the complicated links between digital culture, game play and identity in young people's lives (Stevens et al, 2008). A related set of difficulties comes into play when the educational potential of games is discussed without reference to the role of teachers in games-based classrooms, or when games are represented as complete, 'teacher-proof, inherently appealing knowledge packages that will generate learning across all student cohorts, regardless of where or when or how they are introduced into a classroom.

This 'black boxing' of digital games as 'learning machines' (Prensky, 2005) has informed a growing body of literature focused on such things as the 'nature' and 'potential' of games to contribute to student learning (New Media Consortium, 2012); the reasons why games are 


\section{Catherine Beavis et al}

particularly suited to educational purposes in the twenty-first century; the inherent appeal of games to students represented as 'digital natives' (Prensky, 2001); the unique affordances serious games provide to experientially understand complex matters (Derryberry, 2007); and the particular domains of schooling that could benefit from integration of digital games (Young et al, 2012). Much of this literature, while recognising elements such as the affordances and 'qualities' of games, adopts a relatively uncritical stance towards matters of take up, suggesting that games will almost automatically improve student engagement, experience and achievement. 'Black box' views of games marginalise the role of context and the ways in which teachers impact upon what games achieve in school. Yet, as Egenfeldt-Neilson (2006) notes:

Researchers are consistently finding that teachers play an important role in facilitating learning with videogames, in steering use in the right direction and also in providing an effective debriefing that can catch misperceptions and interesting differences in student experiences while playing. (p. 205)

Sociocultural perspectives on interactions between games, school and learning, foreground ways in which the introduction of games into school contexts is considerably more complex than is sometimes acknowledged. Games (serious or otherwise) do not exist in isolation and game play is linked to issues of identity, performance and sense of self (de Castell \& Jensen, 2003; Beavis, 2004; Gee, 2007; Chee, 2011). Amongst other things, this means there is no single way in which games will be understood and engaged within diverse schooling contexts because factors such as gender, socio-economics, cultural background as well as interest, competence and prior experience all shape what students bring to a games based environment (Beavis \& Charles, 2007; Dezuanni, 2010; Chee, 2011; Young et al, 2012).

Yet, as Pelletier (2009) notes, much of the literature exploring games, learning and schools celebrates the learning 'potential' of games and game play while consistently failing to attend to the social and institutional contexts which shape play in the first place. What a games based learning environment in school actually becomes is closely tied to the way teachers think about games including what they believe can or cannot be achieved with games and how they believe games should or should not be used. Squire, for example, argues that " $t]$ he educational value of game play comes not from the game itself, but from the creative coupling of educational media and effective pedagogy to engage students in meaningful practices' (2002, p. 10). Similarly, Mehrotra and others (2012) suggest that while different games variously support learning of a range of kinds, the ways in which teachers work with games has a direct impact upon the successes or failures of games based initiatives, with different outlooks and expectations on the teachers' part having material consequences.

For schools to fully benefit from the use of digital games in the classroom, it is necessary both to recognise the influence of context on how games are understood and played, and to understand the important role that teachers play in both shaping and negotiating these contextual conditions. While individual studies do exist which focus specifically on the ways in which teachers make a difference to games based learning outcomes, the role of teachers within games based learning more generally has been identified as a neglected part of the research within games/education literature, and one which warrants close and ongoing attention (Connolly et al, 2012; Perrotta et al, 2013). This article is directed towards addressing this absence.

The article proceeds from four assumptions. First, compelling evidence of the potential for games to impact positively upon the learning of diverse learners in primary and secondary schools justifies ongoing exploration of games and schooling (Connolly et al, 2012; Young et al, 2012; Perrotta et al, 2013). Second, this potential impact is closely tied to how teachers work with games (and the games that they choose). Third, teachers' beliefs about what is (or is not) possible with games will inevitably influence the decisions that they make about how, when, and for what specific purposes they bring digital games into their classrooms. Fourth, any attempt to better understand the broad phenomenon of games in education needs to pay attention to the beliefs and practices of the teachers who are at the forefront of the decision making about how, when and if games will be brought into classrooms.

With this as our starting point, we draw upon data collected for a large scale, mixed methods research study focusing on literacy, learning and teaching with digital games in Australian classroom, to focus explicitly on the attitudes, expectations and understandings related to digital 
games and games based learning held by diverse teachers at the beginning of the project. We seek to identify the beliefs about games that motivated teachers' participation in a digital games research project while focusing, as well, on concerns that teachers express about risks or limitations of such a project. Our aim throughout is to develop a detailed picture of the mindsets that teachers bring to games-based learning environments, and the relevance of these mindsets to broader debates about the relationship between games, learning and school.

\section{Serious Play: an introduction to a research project}

This article draws upon data from the project Serious Play: digital games, learning and literacy for twenty first century schooling. Funded by the Australian Research Council, over a three-year period the project investigates what happens to literacy and learning, curriculum, pedagogy and assessment when digital games are introduced into schools. It explores ways in which young people's out of school experience of games and games-based learning can be used to support literacy, creativity and disciplinary learning through the use of both commercial and 'educational' (serious) games; and how this learning is best assessed.

The study involves partners across two Australian states - Queensland and Victoria - and brings together a large research team with teachers in five primary schools and five secondary schools, across a variety of curriculum areas, in state and private jurisdictions, encompassing a range of socio-economic and geographic diversity, and mixed and single sex schools. Over 400 students participated in the study in its first year, ranging in age from early primary - grade 1 (5-6 year olds) through to middle secondary school - grade 9 (14-15 year olds), together with teachers from the 10 schools. Teachers and schools participating in the project were not selected as representative of a larger cohort of teachers across the country. Rather, teachers were working in schools that had opted in to the project as industry partners. This means that the schools, and in many instances the participating teachers, were already interested in (and in some cases experienced with) using games in the classroom. That is, these teachers (or their schools) already had a view that games had something to offer, but the range of experiences teachers had had personally as game players, or in using games in the classroom, varied widely.

The first phase of the project was a mapping exercise, during which we surveyed teachers and students, and conducted interviews with participating teachers across the 10 schools. Interviews canvassed a range of issues to do with teachers' expectations and experiences as games players (or not), and the hopes and fears they held about what might be achieved through using games in the classroom. Specifically, questions addressed such matters as:

- Teachers' personal experience as gamers

- Teachers' knowledge about games

- Teachers' attitudes towards games being used in schools: benefits and potential

- 'Teachers' concerns about the use of games in schools

Following transcription, a broadly based thematic approach was adopted for the analysis of the data. In the approach chosen, a theme is 'a pattern found in the information that at the minimum describes and organises possible observations or at the maximum interprets aspects of the phenomenon' (Boyatzis, 1998, p. vii). Boyatzis goes on to note that themes may be initially 'generated inductively from the raw information or generated deductively from theory and prior research' (1998, p. vii). In this project the line between inductive and deductive is blurred. Working within this broad framework we set no limits around the number of potential themes that might emerge. Nor were we determined to prove that one particular theme was more powerful than any other. Rather, we sought to identify and hear the granulated specificity of these teachers' priorities, hopes and concerns proceeding from the position that teachers' beliefs about games will shape not only what they imagine games can achieve, but also by extension how they work with games, and the ways this intersects with other aspects of their teaching.

We approached the coding of the data with knowledge of major themes existing in previous research and worked initially to separate teachers' beliefs into two categories: those that might be seen as optimistic or positive about what games could/should/might help teachers achieve in classrooms and those that were rather more cautious in terms of beliefs about the potential limitations of games, or issues that people working with games would need to be aware of. As the 


\section{Catherine Beavis et al}

coding progressed a third theme emerged: issues that teachers felt were things they did not have to worry about (even though these particular issues have been included in some other literature as common sources of teacher concern).

Given the tenor of much public rhetoric about games and learning this approach is particularly important. As Selwyn (2011) notes, at the present time, a 'proof of concept' mentality persists in much educational technology scholarship, often directing researchers and writers away from examining the compromised and problematic everyday uses (and non-uses) of technology in education' (p. 717). In seeking to understand and identify these teachers' expectations, hopes and apprehensions, this research provides a valuable counter to both overly pessimistic representations of the way games damage children and overly celebratory 'booster' rhetoric within debates about games and education. The experiences and expectations of teachers such as those in this study are much needed to provide insights and practical guidance for those involved in all aspects of games based learning - theory, practice and research.

\section{Teachers’ Beliefs about Games: the optimistic, the cautious and the non-concerns}

The themes identified are drawn from participating teachers across all 10 schools within the project, with specific quotes and ideas below drawn from 16 of the project's teachers. As outlined above, for the purposes of this article we have grouped teachers' beliefs about games and learning into two broad sections: the first explores the optimistic beliefs teachers expressed about the potential educational benefits of games, and what games might help them achieve in schools. The second explores the teachers' beliefs about the limitations of, or potential issues to address, in regards to the use of digital games in school. In addition, a third section - 'non-concerns' highlights potential problems identified in gaming literature that this particular group of teachers did not seem worried about.

\section{The Optimistic: why games are good for schools}

The majority of the comments made by the teachers related to the broad theme of optimistic beliefs. The following sub-themes featured in interviews conducted with teachers at all participating schools.

Games are engaging, motivating, fun. By far the most common claim within the teacher interviews were that games were 'engaging' and would, as a result, improve student learning. Similar to teachers interviewed in other studies (Millstone \& BrainPOP, 2012; Sandford et al, 2006), the participants in this project commented repeatedly on the fun and engaging nature of digital games:

They [students] really totally engage. They absolutely love it.

When you are playing, you engage. Because you are in there. Games have that captivation.

Above anything else, kids are very engaged by the activity of playing games. It's a bit more personal for them; they are in more control and dictating exactly how it should go.

Teachers noted the emotional response linked to playing games in schools:

Their emotional response to the game, when they are getting higher and higher, and the pressure's on and their excitement levels are up, they are jittering.

One thing that can really engage learners is doing something a little bit different, physically, than what they normally would.

Our experience with JustDance, as a shared strategy with performing arts teachers, for our professional development, brought a lot of smiles.

In a similar vein, it was frequently claimed that games were almost inherently motivating and would therefore help keep students' attention:

Irrespective of what game it is - as soon as you mention a competition or there's a chance of winning something or likewise, whether it's in the game or a one-on-one maths competition, the 
boys are very engaged. So that's the main element, I think. It's obviously engaging the boys and then moving on from there.

Games are learning in disguise. The beliefs that games are engaging, fun and motivating, are reflected in a second theme within the data: that games allow teachers to introduce school work in disguise:

They don't see it as so much maths, or whatever it might be. They just see it as a bit of fun. But to me it's reinforcing some of the key things that we're trying to get through here in the classroom.

I want the kids to have fun. They don't perceive it as 'learning', but it is.

Claims about the motivational potential of games, and their inherently 'fun' nature are reflected in an unstated but powerfully implied assumption that where there is fun, and motivation, then learning is likely to occur. This can be expressed in the relatively straightforward idea that fun + motivation + school-in-disguise will equal learning. This was a powerful theme in the teacher interviews:

Kids absolutely love it and get so much enjoyment out of it and they're learning in the process and they're engaged by it. I mean you couldn't ask for anything more than that.

Games develop general, generic, 'twenty-first century' skills. The third set of benefits associated with digital games relate to their potential to develop in students the sorts of abilities and dispositions that have been variously described as 'general capabilities' (Australian Curriculum Assessment and Reporting Authority, 2013), skills for a knowledge economy (Thomas \& Seely Brown, 2011) or 'twenty-first century skills' (Klopfer et al, 2009). While there is a considerable amount of disagreement in scholarship about the loose ways in which the label 'twenty-first century skills' is employed (Facer 2011a), there was agreement amongst many of the teachers that some of the most valuable outcomes from games based projects were the opportunities they provided for students to develop skills rather than content knowledge. There were several dimensions to these claims.

First, it was frequently claimed that games enhanced creativity: this was seen as particularly significant given public rhetoric about both the need to foster creativity within the schooling system, an increasing emphasis within the new Australian curriculum on the importance of creativity, and diverse literature which maps the apparent difficulties of achieving 'creativity' outcomes within the confines of formal schooling (see for example Craft, 2005; Burnard \& White, 2008). Teachers noted that:

Gaming is one of those areas that does actually facilitate creativity and innovation, it gives them the chance to really work their imagination and keep that stuff going, and from industry, from everywhere, there is that demand on education to produce creative and innovative thinkers, but hardly any education actually does that.

Thinking skills and problem solving skills were also identified as important benefits of working with digital games:

- Thinking skills

I prefer games personally for how they make you think, that they can teach you think outside the square and problem-solve and all that sort of thing.

- Problem solving

I'm sure I, at some stage, thought it was all just a bit mindless. But no ... they're not just sitting there dumbly in front of a computer. There's a lot of interaction, a lot of thinking a lot of [problem solving].

I prefer the games for how they make students think and they can teach them to think outside the square. As well, they train on problem-solving skills.

Teamwork and collaboration were also identified as potential benefits both within and across schools, with teachers noting that:

I'm also interested in the collaborative stuff. The Minecraft example is really interesting. Because from the educators perspective you have to think about how to manage that environment and how much freedom to you give to them and say just go for it, that's really interesting I think. 


\section{Catherine Beavis et al}

And how they are sort of socially organising themselves. You know, with Minecraft we've got 140 kids and in that environment it's raising really interesting questions about social organisation.

We connect with schools in other countries. We have made links with a school in the [United]

States and we also have a sister school in South Africa.

Comments such as this are common within games literature as teachers regularly identify thinking skills, problem solving skills and collaboration as benefits that flow from working with games (McFarlane et al, 2002).

On a related noted, several teachers spoke about the potential for games based learning environments to encourage communication, and to provide new ways for learners to communicate their understandings. This was also linked to opportunities for students to either develop or improve social skills through collaborative game based interactions:

So the communication, it's not just about the numbers it's about the communication, the social skills, the interaction. They are developing their social awareness. How do I ask someone? How do I not offend someone by giving them an answer or helping them out? So it's just a broad spectrum I'm finding of opportunities.

Teamwork4 and working together to come up with something, but also just having the ability to present in front of us and share their ideas.

Games cater for diversity. While the subthemes mentioned to date generally refer to the potential for games to help all learners, there was also a significant amount of data relating to the potential for games to benefit some learners in particular ways. Games were regarded as almost universally appealing to all potential students. At the same time, teachers were conscious of the fact that games might be more engaging for some students than for others. One teacher noted, for example:

There was some resistance from kids, who are not into computer games; they don't play them in their own time. They are not interested in finding out how it works, so they are turned off.

That being said, there were also several claims made about the potential for games to benefit learners who might be disengaged within a typical or traditional classroom context. The two most common claims made in this regard related to achievement level and gender. Teachers noted the potential for students to proceed at different rates:

The person who's the most challenged can still succeed, whereas the really clever ones can still be challenged.

[we've] seen strength in other kids that don't shine or do really well.

One teacher commented that working with games allowed him to respond to the particular learning needs of a child with Down's Syndrome. Others claimed that games were particularly motivating for boys:

Particularly, working in a boys' school, straightaway, you talk games and the boys are engaged straight away.

You talk games and boys are engaged right away.

The Cautious: things that need to be thought about

The themes explored to this point reflect a remarkable degree of consistency across the diverse teachers in the project. In number and consistency, the optimistic beliefs of teachers far outweigh themes under the second broad category of beliefs: areas of caution. There was considerable variety in terms of the issues linked to this theme and also far less consistency across teachers. Each theme presented in this next section of the article, therefore, need to be understood as reflecting the views of generally only one or two teachers. Nevertheless, it is this very diversity in terms of the range and scope of concerns that are significant for researchers seeking insight into factors that shape teachers' choices to work with digital games.

The novelty might wear off. A first concern speaks back to the original claims that games would be automatically engaging for most or all students. Teachers noted that although this may 
well be the case, it would be possible for this appeal to be lost if the novelty factor of seeing games in their classroom began to wear off:

To really capture - to really get these kids involved, it's got to be something - they've got to see the mystery in it. I mean, they like playing those other things just briefly too. But how long does the novelty of it last?

And while in some contexts teachers spoke about the engaging nature of games, they also noted that any individual game could quickly become boring once students had mastered the challenged, or completed the particular task:

The GoldRush game was just an introductory lesson. They got a bit sick of it after one lesson when they nearly finished the game. They worked out they could get as much money as they could.

Teachers could lose control. A different concern relates to the impact of games on teachers' control of learning and the learning environment. This issue has been identified in other studies, with teachers expressing concerns to varying degrees. While in some instances (e.g. Sandford et al, 2006) teacher anxieties on this count turned out to be less than anticipated, in others, (e.g. Merchant, 2013) loss of control of student behaviour in the in-games world was a significant issue. Issues of control were raised by teachers in this study a range of ways. One teacher expressed an anxiety about the potential challenges to their sense of identity:

It turns weird if my role is becoming more of an explainer and less of a teacher. Such as just saying how to play the game and not teaching the topics.

Another spoke about the difficulties of controlling what students were doing and how they were progressing:

The scope is too large, so I can't control where the kids are up to and I can't manage the learning associated.

A third linked a possible loss of control to concerns about their sense of personal competence:

I feel I'm probably still not autonomous enough in understanding how games can be used, and I'd like to improve that.

And a fourth expressed anxiety about games being seen as a source of information when teachers could not be sure if the information was reliable:

For some of the games, we don't know who has created them or what they are relying on for information. So you'd have to be a reliable source and designer that we know that whatever's in there is up to date, accurate information.

The limits of time and resources. This challenge is a familiar one in the literature and relates to concerns about resources - of time and technology:

There is no real time frame for finishing.

The lack of time we have in the computer labs, and if computers are down, or something

happens can impact on our lesson.

Will students know they are learning? In the previous section we noted the ways in which some teachers celebrated the ways that games based classrooms could almost obscure the fact that students were learning. The other side of this reflection is seen in teachers' concerns that this might impact negatively upon students if they don't understand that they are (or have) been in a learning environment not just a 'play' environment. As Francis (2006) notes, one of the problems found in some games based interventions was that 'students became so engaged with the activity of gaming that the educational focus of the activity was lost' (p. 2). This concern was echoed by one of the teachers in our project, expressing the view that the educational focus and purpose of games based learning must be deliberate and overt:

Sometimes I get worried about that with some of the games that we do. That they don't always get the deeper benefits of it. They just see the novelty factor. 


\section{Catherine Beavis et al}

These were the main sources of concern expressed at the outset of this project. Just as interesting, however, are the factors that these particular teachers did not seem to be concerned about, even though literature (and popular discourse) suggests that these are common obstacles faced by educators wishing to work with games in their classrooms.

\section{The non-concerns}

We were surprised to find that despite the prevalence of concerns with threats and problems in much popular debate when games and education are thought about in the same breath, there were a number of topics that simply did not emerge.

Despite anxieties about violence and 'inappropriate' content that characterise periodic media panics about games, virtually no concern was expressed about the potentially inappropriate nature of games (in terms of violence or unsuitable adult themes) with respect to students' out of school games, or games that might be selected for use in schools.

Similarly, while some literature which claims parents are a major obstacle to the introduction of games into classrooms (Pepe, 2011) the teachers participating in this project did not see parental attitudes as any real impediment to their use of games:

I guess we'd have to keep them informed as to what they need to do. It's a bit of a tricky one, but I think personally, just looking at my class in particular, they seem to be very flexible in regards to their learning and obviously, they want the best for their kids. So they're definitely open-

minded and open to what we've suggested.

Nor did participating teachers express concerns about the impact of factors such as home access to technology, games or the internet on students' attitudes towards, or competence within, broad fields of gaming. When it was noted that not all students have the same access to gaming technology or the internet at home, this was seen as an aberration rather than an obstacle: something that did not require significant time or attention. There was also virtually no concern expressed about the potential cost of the games or game playing technologies for the school.

\section{Discussion}

In both what is said and what is not said, the data explored above provides interesting insights into teachers' understandings about the potential benefits and possible limitations associated with digital games. Teachers' comments provide valuable insights for those researching in the broad field of digital games: insights with implications for those working with teachers in this area. In reflecting on these comments we are influenced by the 'teachers first' position articulated by authors such as Bigum and Kenway (1998): that is, the belief that if we are hoping to introduce any new technologically mediated or games based activity into schools in a way that generates maximum benefits for learners we must recognise the need to make teachers' professional learning needs a priority. This commitment must go beyond attempts to provide information about what games are available, to encompass, instead, opportunities to understand more fully the nature and affordances of specific games and how they might be used, and to reflect upon the full range of factors that impact upon what happens to learning when games are introduced into schools.

A central observation to be made is that the teachers in the project were overwhelmingly positive about the potential for games to impact positively upon learning environments. Their comments are consistent with widely rehearsed and familiar claims in gaming literature about the capacity of games to engage and motivate students thereby increasing their opportunities to acquire valuable skills and learn new material. The largely optimistic tone of many of the teachers' comments provides a valuable counterpoint to claims by authors such as Prensky (2005) who suggests that teachers (largely by virtue of their age) will automatically see games as 'trivial'.

Looking closely at the data does, however, demonstrate the ways in which this optimism is paralleled by several important silences. In the remainder of this article we explore what might be hidden or obscured. In exploring the silences in teachers' comments our goal is to highlight issues that might warrant further attention, and to provide a baseline against which to map changes in teachers' attitudes, understandings and experiences over time. 
First, much of the data emphasises the almost magical properties of games to engage, inspire and teach students. In other words, even the teachers themselves seemed prone to overlook the crucial role that they would play in how games were experienced and responded to by diverse students. Attention needs to be paid to the pedagogical strategies and views of learning that teachers draw upon to work with games (Francis, 2006; Chee, 2011); and the crucial role of the teacher in determining whether games are used in effective and appropriate ways (Beavis, 2012).

Second, seeing games as inherently motivating also has the potential to construct them more as a springboard to learning, than a means of learning in themselves. This position might be expected to change as teachers in the project become more experienced and skilful in the use of games, but it is also reflective of wider discourses within education that legitimate games as 'motivation' without venturing into more problematic territory related to the nature of disciplinary knowledge and formal school curriculum.

A third, related, point concerns the ways in which celebrating the potential for games to produce 'learning in disguise' contributes to a problematic representation of learning as a sort of 'nasty pill' that must be 'sugarcoated with fun and games' (Papert, 1996, pp. 50-51). Papert's argument is that such a mindset can lead to the belief that learning is to be endured, rather than 'embraced and enjoyed' (pp. 50-51). This raises questions about whether or not we want students to be able to recognise when they are learning, and, by extension, to develop some sort of metacognitive understandings about learning and about the subject. Can this happen if games are understood as Trojan horses smuggling learning into unaware students' lives?

One of the most powerful causes of teacher optimism was the belief that games contributed to the development of skills and capacities that exceed the boundaries of disciplinary study: collaboration, problem solving, thinking skills and so on. Such observations are consistent with those noted in other studies (McFarlane et al, 2002; Egenfeldt-Nielsen, 2006). However, while teachers were optimistic about the potential for games to engage learners, there was less discussion of the potential for games in terms that relate specifically to existing assessment structures and foci. While there was widespread agreement that every curriculum area could find a way to work with digital games, teachers were more likely to refer to generic skills (rather than curriculum objectives) when discussing the educational benefits of games.

For some teachers at least there was agreement that games 'could' be relevant to all curriculum areas (with only physical education commonly given as an area where games would perhaps not be applicable) but at the time of the interviews this potential was not discussed with confidence. There was also some doubt about whether games were best used to introduce concepts or reinforce concepts. This highlights among other things the need for additional opportunities for teachers to be given sustained opportunities to explore the nature and affordances of various kinds of games, the relationship between games and different curriculum areas, and the difference between using games to introduce new concepts or content on the one hand, or using them to reinforce what has already been learnt on the other.

As previously noted, a striking pattern within the data was a recurring tendency to represent games as universally appealing to all students. While the teachers knew their students, and might be expected to have an implicit understanding of difference and the phantasmagoric nature of 'universal appeal', the lack of explicit discussion of this issue risks glossing over differences in gender, class, cultural background, all of which can have a profound impact upon how/when/why students would be engaged or motivated in working with specific games. Similarly, there was no explicit discussion of the impact of socio-economics nor the ways in which out-of-school access to games or technologies might influence in-school outcomes, consistent with points made by Facer (2011b). When teachers did speak about such things as the appeal or benefits of games to particular sub-groups of students (the most common of which was boys), they tended to represent the members of that group as generally the same, a trend that gender research has been problematising in diverse school contexts for many years (Rowan et al, 2002; McCaughtry, 2004; Martino \& Kehler, 2007).

While the positive disposition towards the potential of games to achieve diverse outcomes is welcome, it is important that this enthusiasm does not obscure the important fact that students' existing relationships come with them into games-based classrooms. Although it has sometimes been claimed that, when playing, gamers enter what Huizinga (1950) once described (in a predigital era) as a 'magic circle' - a place set apart from normal life - the idea that game play creates a 


\section{Catherine Beavis et al}

circle within which players are exempt from the rules or traditions of 'ordinary' life has been widely critiqued by authors who note that the rules of ordinary life intersect with the rules that apply in a gaming context (Consalvo, 2009). Students who have previously had troubled or troubling interactions with each other will not automatically find themselves in a new or neutral relationship simply because games have been added into the context. Despite observations made about the ability of games to generate teamwork, collaboration and cooperation, 'gamers' are usually the same 'kids' they were before they entered a game environment and this needs careful and close attention.

The data relating to teachers' beliefs about the risks or limitations of working with digital games provides a similarly interesting set of challenges.

To begin with, although there is a great deal written about the inappropriate content associated with many games, teachers expressed little concerns with this area. They were clearly comfortable in their ability to demonstrate that, although some games might, indeed, be inappropriate for use with children or schools, there is a rich and variety of games available that were entirely appropriate in form and content.

Similarly, the teachers also expressed confidence in their ability to 'sell' games to children's parents. This suggests that parental attitudes need not be the barrier they are sometimes represented as. This is a powerful reminder of the role that teachers play in shaping the gaming context and representing games as legitimate parts of a learning environment.

It is also interesting to note that there were very few concerns raised about:

- Limitations in terms of students' prior experiences with games

- Limitations in terms of students' access to games at home

- The possible tensions that may arise when games are brought into school contexts.

\section{Conclusion}

This article is based upon the related beliefs that games have the potential to impact positively upon student engagement and student learning, and that the context in which games based learning takes place has an impact upon what actually happens. Teachers play a central role in both the creation and negotiation of context and their beliefs and understandings about games shape how, where, when and why they work with games with diverse learners.

The data explored above suggest that teachers entering the Serious Play project did so with some very specific ideas about what games would add to students' learning. The grounded but optimistic nature of these claims is an important counterpoint to both overly hyped up representations as games as learning machines and overly negative assumptions that games will only do damage to students/classrooms/schools. They also provide a basis from which to explore further the intersections between pedagogical decision making and issues of identity, context and the multiple factors which influence what actually happens when games are brought into schools.

The ongoing work needed to develop 'real world accounts' of what happens when games meet classrooms as called for by authors such as Perrotta et al (2013) and Bigum (2012) must be accompanied by serious efforts to understand how and why teachers begin to work with games in the first place. Focusing on teachers' understandings, expectations and beliefs about games is a vital component of any broader attempt to better understand the relationship between games, school and learning.

\section{References}

Australian Curriculum Assessment and Reporting Authority (2013) The Australian Curriculum Version 5.0. http: / / www.australiancurriculum.edu.au/Download/F10

Beavis, C. (2004) 'Good Game': texts and community in multiplayer computer games, in I. Snyder \& C. Beavis (Eds) Doing Literacy Online: teaching, learning and playing in an electronic world. New Jersey: Hampton Press.

Beavis, C. (2012) Critical Perspectives, Enabling Classrooms and Digital Games: challenges for teachers and researchers working with games-based learning, in G. Biswas, L.-H. Wong, T. Hirashim \& W. Chen (Eds) Proceedings of the 20th International Conference on Computers in Education. Singapore: Asia-Pacific Society for Computers in Education. 
Beavis, C. \& Charles, C. (2007) Would the 'Real' Girl Gamer Please Stand Up? Gender, LAN Cafes and the Reformulation of the 'Girl' Gamer, Gender and Education, 19(6), 691-705. http: / / dx.doi.org/10.1080/09540250701650615

Bigum, C. (2012) Schools and Computers: tales of a digital romance, in L. Rowan \& C. Bigum (Eds) Transformative Approaches to New Technologies and Student Diversity in Futures Oriented Classrooms: future proofing education. Dordrecht: Springer. http:/ / dx.doi.org/10.1007/978-94-007-2642-0_2

Bigum, C. \& Kenway, J. (1998) New Information Technologies and the Ambiguous Future of Schooling: some possible scenarios, in A. Hargreaves, A. Lieberman, M. Fullan \& D. Hopkins (Eds) International Handbook of Educational Change, Part One. Dordrecht: Kluwer. http:/ / dx.doi.org/10.1007/978-94-011-4944-0_19

Boyatzis, R. (1998) Transforming Qualitative Information: thematic analysis and code development. Thousand Oaks, CA: Sage.

Burnard, P. \& White, J. (2008) Creativity and Performativity: counterpoints in British and Australian education, British Educational Research Journal, 34(5), 667-682. http: / / dx.doi.org/10.1080/01411920802224238

Chee, Y.S. (2011) Learning as Becoming Through Performance, Play, and Dialog: a model of game-based learning with the game Legends of Alkhimia, Digital Culture and Education, 3(2), 98-122.

Connolly, T.M., Boyle, E.A., MacArthur, E., Hainey, T. \& Boyle, J.M. (2012) A Systematic Literature Review of Empirical Evidence on Computer Games and Serious Play, Computers \& Education, 59, 661-686. http:// dx.doi.org/10.1016/j.compedu.2012.03.004

Consalvo, M. (2009) There is No Magic Circle, Games and Culture, 4(4), 408-417. http: / / dx.doi.org/10.1177/1555412009343575

Craft, A. (2005) Creativity in Schools: tensions and dilemmas. New York: Routledge. http:/ / dx.doi.org/10.4324/9780203357965

Davidson, D. (2008) Beyond Fun: serious games and new media. Pittsburgh, PA: Carnegie Mellon Press.

de Castell, S. \& Jensen, J. (2003) Serious Play, Curriculum Studies, 35(6), 649-665. http: / / dx.doi.org/10.1080/0022027032000145552

Derryberry, A. (2007) Serious Games: online games for learning. San Jose, CA: Adobe Systems Incorporated.

Dezuanni, M. (2010) Digital Media Literacy: connecting young people’s identities, creative production and learning about videogames, in D.E. Alvermann (Ed.) Adolescents' Online Literacies: connecting classrooms, media, and popular culture. New York: Peter Lang.

Egenfeldt-Nielsen, S. (2006) Overview of Research on the Educational Use of Video Games, Digital Kompetanse, 1(3), 184-213. http://www.itu.dk/people/sen/papers/gameoverview.pdf. (accessed 12 September, 2013).

Facer, K. (2011a) What Futures for Digital Literacy in the 21st Century? in L.K. Stergioulas \& H. Drenoyianni (Eds) Pursuing Digital Literacy in Compulsory Education, pp.223-240. New York: Peter Lang.

Facer, K. (2011b) Learning Futures: education, technology and social change. London: Routledge.

Francis, R. (2006) Towards a Theory of a Games-based Pedagogy. Paper presented at Innovating E-learning 2006: transforming learning experiences, JISC conference, 27-31 March, held online. http:/ / www.onlineconference.net/jisc/ content/Francis\%20-\%20games\%20based\%20pedagogy.pdf (accessed 12 September, 2013).

Gee, J.P. (2007) What Video Games Have to Teach Us About Learning and Literacy, revised edn. New York: Palgrave Macmillan.

Huizinga, J. (1950) Homo Ludents: a study of the play element in culture. Boston, MA: Beacon.

Klopfer, E., Osterweil, S. \& Salen, K. (2009) Moving Learning Games Forward: obstacles, opportunities and openness. The Education Arcade. http: / / education.mit.edu/papers/MovingLearningGamesForward_EdArcade.pdf

Martino, W. \& Kehler, M. (2007) Gender-based Literacy Reform: a question of challenging or recuperating gender binaries, Canadian Journal of Education, 30(2), 406-431. http: / / dx.doi.org/ 10.2307/20466644

McCaughtry, N. (2004) Learning to Read Gender Relations in Schooling: implications of personal history and teaching context on identifying disempowerment for girls, Research Quarterly for Exercise and Sport, 75(4), 400-412. http: / / dx.doi.org/10.1080/02701367.2004.10609173

McFarlane, A., Sparrowhawk, A. \& Heald, Y. (2002) Report on the Educational Use of Games, Teachers Evaluating Educational Media (TEEM). London: Department for Education and Skills. 


\section{Catherine Beavis et al}

Mehrotra, S., Chee, Y.S. \& Ong, J.C. (2012) Teachers' Appropriation of Game-based Pedagogy: a comparative narrative analysis. Paper presented at the 20th International Conference on Computers in Education, 26-30 November, in Singapore.

Merchant, G. (2013) 'I Oversee What the Children Are Doing': challenging literacy pedagogy in virtual worlds, in G. Merchant, J. Gillen, J. Marsh \& J. Davies (Eds) Virtual Literacies: interactive spaces for children and young people. London: Routledge.

Millstone, J. \& BrainPOP (2012) Teacher Attitudes about Digital Games in the Classroom. New York: Joan Ganz Cooney Center at Sesame Workshop.

New Media Consortium (2012) NMC Horizon Report 2012 K-12 Edition. http:/ / www.nmc.org/publications/ 2012-horizon-report-k12

Papert, S. (1996) The Connected Family: bridging the digital generation gap. Atlanta, GA: Longstreet.

Pelletier, C. (2009) Games and Learning: what's the connection?, International Journal of Learning and Media, 1(1), 83-101. http:/ / dx.doi.org/10.1162/ijlm.2009.0006

Pepe, K. (2011) A Study on the Playing of Computer Games, Class Success and Attitudes of Parents to Primary School Students, Educational Research and Reviews, 6(9), 657-663.

Perrotta, C., Featherstone, G., Aston, H. \& Houghton, E. (2013) Games-based Learning: latest evidence and future directions. Slough: National Foundation for Educational Research.

Prensky, M. (2001) Digital Natives, Digital Immigrants, Part 1, On the Horizon, 9(5), 1-9. http: / / dx.doi.org/10.1108/10748120110424816

Prensky, M. (2005) In Educational Games Complexity Matters. Mini-games are Trivial - but 'complex' games are not. An Important Way for Teachers, Parents and Others to Look at Educational Computer and Video Games. http:/ / www.marcprensky.com/writing/Prensky-Complexity_Matters.pdf

Rowan, L., Knobel, M., Bigum, C. \& Lankshear, C. (2002) Boys, Literacies, and Schooling: the dangerous territories of gender-based literacy reform. Buckingham: Open University Press.

Sandford, R., Ulicsak, M., Facer, K. \& Rudd, T. (2006) Teaching with Games: using commercial off the shelf computer games in formal education. Bristol: Futurelab.

Selwyn, N. (2011) Editorial: in praise of pessimism - the need for negativity in educational technology, British Journal of Educational Technology, 42(5), 713-718. http:/ / dx.doi.org/10.1111/j.1467-8535.2011.01215.x

Stevens, R., Satwicz, T. \& McCarthy, L. (2008) In-game, In-world: reconnecting video game play to the rest of kids' lives, in K. Salen (Ed.) The Ecology of Games: connecting youth, games and learning. Cambridge, MA: MIT Press.

Squire, K. (2002) Cultural Framing of Computer/Video Games, Game Studies, 2(1). http:/ / www.gamestudies.org/0102/squire/

Thomas, D. \& Seely Brown, J. (2011) A New Culture of Learning: cultivating the imagination for a world of constant change. Lexington, KY: CreateSpace.

Young, M., Slota, S., Cutter, A., Jalette, G., Mullin, G., Lai, B., et al (2012) Our Princess Is in Another Castle: a review of trends in serious gaming, Review of Educational Research, 82(1), 61-89.

http: / / dx.doi.org/10.3102/0034654312436980

CATHERINE BEAVIS ${ }^{\star}$ is Professor of Education at Griffith University. Catherine’s research expertise centres on the changing nature of text and the implications for literacy, education and schooling of young people's engagement with digital culture and the online world. She researches in the areas of English curriculum, pedagogy and assessment; digital culture and computer games; digital literacy and new literacies and games-based learning. Correspondence: c.beavis@griffith.edu.au

LEONIE ROWAN is a senior lecturer in the School of Education and Professional Studies at Griffith University. Her research interests relate to the social contexts of education, educational justice, digital learning, gender and the multiple ways in which educators in schools, universities and other learning environments can meet the needs of diverse student populations.

MICHAEL DEZUANNI is a senior lecturer and researcher in the field of digital cultures and education, which includes film and media education, digital literacies and Arts education. He is the 
Deputy Director of QUT's Children and Youth Research Centre and is a member of the Faculty of Education and Creative Industries Faculty. The aim of both his teaching and research is to explore the most effective, productive and meaningful ways for individuals to gain knowledge and understanding of the media and technologies in their lives.

CHRISTY MCGILLIVRAY is the Victorian research assistant working for the Serious Play project and is a $\mathrm{PhD}$ candidate. Her doctoral research is undertaken as a part of an ARC discovery grant investigating leadership practices in Australian higher education with Professor Jillian Blackmore and Dr Naarah Sawers. Her research interests are broadly focused on social justice and equity in education.

JOANNE O'MARA is a senior lecturer at Deakin University. Her research investigates innovative pedagogy and practices and the spatial and temporal dimensions of teachers' work. She has a particular interest in the areas of new literacy studies and the arts and is passionate about her ongoing series of research projects in the areas of drama education pedagogy and practices, digital games, emergent literacies and new textual practices.

SARAH PRESTRIDGE's research examines teachers' engagement in ICT professional development that intends to enable them to understand digital pedagogy and how this differs from their current practice. This includes a focus on teacher beliefs, pedagogies and teacher change. The conceptual base of her research builds on the professional development model developed in her doctoral research. Current directions in this area identified the need for further research into the benefits of teachers engaging in professional development in virtual spaces.

COLLEEN STIELER-HUNT is a research assistant for the Serious Play project and a $\mathrm{PhD}$ candidate at the University of the Sunshine Coast. Her doctoral research addresses the ways in which teachers use digital games in the classroom.

ROBERTA THOMPSON is the Queensland research assistant for the Serious Play project and is a $\mathrm{PhD}$ candidate. Her doctoral research explores the ways in which young teen girls engage with new technologies and social media to navigate and manage peer relationships. Teaching areas include supportive classroom environments and socialisation in the middle years.

JASON ZAGAMI lectures in Education at Griffith University, Gold Coast, Australia, researching cognition, professional learning and expertise, and all aspects of educational technologies - with a current focus on mobile learning, games in education, augmented reality, virtual environments, neural interfaces, and the emergence of computing as a school discipline.

${ }^{\star}$ Contact author 